\title{
Burden of non-communicable diseases among geriatric Nigerians in a rural hospital in resource-constrained setting of Eastern Nigeria
}

\author{
Gabriel Uche Pascal Iloh", *, Agwu Nkwa Amadi², Abali Chuku ${ }^{3}$ \\ ${ }^{1}$ Department of Family Medicine, Federal Medical Centre, Umuahia, Abia state, Nigeria and visiting Consultant Family Physician, St. \\ Vincent De Paul Hospital, Amurie- Omanze, Imo state, Nigeria \\ ${ }^{2}$ Department of Public Health Technology, Federal University of Technology, Owerri, Imo state, Nigeria \\ ${ }^{3}$ Department of Ophthalmology Federal Medical Centre, Umuahia, Abia state, Nigeria
}

\section{Email address:}

ilohgup2009@yahoo.com(G. U. P. Iloh)

\section{To cite this article:}

Gabriel Uche Pascal Iloh, Agwu Nkwa Amadi, Abali Chuku. Burden of Non-Communicable Diseases among Geriatric Nigerians in a Rural Hospital in Resource-Constrained Setting of Eastern Nigeria. Science Journal of Public Health. Vol. 1, No. 3, 2013, pp. $141-146$. doi: $10.11648 /$ j.sjph.20130103.16

\begin{abstract}
Background: Globally, there is an emerging increase in the population of elder citizens. Despite the process of natural aging, elderly population in addition suffers acute and chronic non-communicable diseases (NCDs) which are often neglected. Aim: This study was aimed at describing the burden (prevalence and pattern) of non-communicable diseases among geriatric Nigerians in a rural hospital in resource-constrained setting of Eastern Nigeria. Materials and Methods: This study was a descriptive hospital-based study of 286 geriatric patients with NCDs out of a total of 872 geriatric patients' population in a rural Hospital in Imo state, South-Eastern Nigeria. The data collected included age, sex and diagnoses. Diagnoses of NCDs were based on clinical method of subjective complaints, objective findings and appropriate laboratory and radio-diagnostic confirmations. Results: Eight hundred and seventy two patients out of a total patients population of 9885 were 65 years and above. The geriatric population constituted $8.8 \%$ of total patients' population. Five hundred and thirty $(60.8 \%)$ of geriatric health problems were due to communicable diseases; two hundred and eighty-six (32.8\%) were due to NCDs and fifty-six (6.4\%) resulted from accidents, trauma and injuries. Of the 286 who had non-communicable diseases $176(61.5 \%)$ were males while $110(38.5 \%)$ were females with a male to female ratio of 1.6: 1 . The top five noncommunicable diseases were hypertension 192 (67.1\%), musculoskeletal disorders 126 (44.1\%), dyspepsia 99 (34.6\%), non-communicable visual impairment 96 (33.6\%), and diabetes mellitus 25(8.7\%) Conclusion: This study has shown that geriatric patients in the study area suffer NCDs with three most common being hypertension, musculoskeletal disorders and dyspepsia. There is therefore the need for preventive action against the scourge of geriatric non-communicable diseases.
\end{abstract}

Keywords: Geriatrics, Hospital, Morbidity, Non-communicable diseases, Rural Nigeria

\section{Introduction}

Globally, there is an emerging increase in the population of elder citizens.[1,2] Although aging is perceived as a natural phenomenon, it can be normal or successful. [3] Normal aging refers to the complex of diseases, disability and impairments that characterize aging. [3,4] However, people vary in the rate at which they manifest indicators of aging, acquire diseases and impairments.[4,5] Successful aging refers to a process by which deleterious effects and impairments are minimized, preserving function until senescence makes continued life impossible.[3] The concept of successful aging is that aging is not necessarily accompanied by debilitating diseases and disability. [5] The elderly person may be able to avoid the complications of cardiovascular diseases even while the circulatory system continues to age by controlling blood glucose levels and body fat percentage.[3-5]

Age is epidemiologically recognized as an independent risk for non-communicable diseases especially cardiovascular diseases.[2,6] In aging process many physiological functions decline (homeostenosis) but normal decline is not usually considered the same as disease.[5] Many of the non-communicable diseases responsible for 
high morbidity and mortality in developing countries affect elderly people disproportionately further magnifying their socio-economic and medical impact.[7,8] As a result, this category of the population is among the greatest contributors to disability-adjusted life years due to noncommunicable diseases.[8]

Health is a subject on the concurrent list in the constitution of the Federal Republic of Nigeria as a result of its importance to the teaming population. As Nigerian population ages, expectation of life and burden of diseases are changing. [9-13] While variability of noncommunicable diseases across different parts of the world is a factor of genetic and socio-environmental conditions such as life-style related factors.[14-18] The prevalence of non-communicable diseases is relatively higher in developed countries but their prevalence and pattern in developing countries such as Nigeria are emerging and are expected to change with aging of the population. $[15,16]$ However, with rapid socio-medical and demographic changes in Nigeria it is likely that diseases transition is occurring. The World Health Organization in their Global Burden of Disease Study described the trends of noncommunicable diseases in developing countries. The study suggested that by the 2020, the proportion of burden of non-communicable diseases in sub-Saharan Africa will increase to somewhere between $26 \%$ and 34\%.[19] Projections indicate that these burden of diseases will increase unless there is interventional commitment to prevention and control.[9]

In Nigeria, the current distribution of resources has been heavily skewed towards maternal and child health as well as biased by the burden of the three big infectious diseases (malaria, tuberculosis and HIV/AIDS), a policy that has left geriatric non-communicable diseases poorly attended to. In resource-poor rural communities of Nigeria, healthcare seeking and utilization of healthcare services by elderly persons are mainly driven and determined by the need for curative services rather than preventive services [20] and this contrasts with what is obtained in United States of America where geriatric patients constituted $24 \%$ of physicians' health maintenance visits.[2] This is probably due to the quality of healthcare in Nigeria among other factors such as social, economic, environmental, cultural and political factors that adversely affect the health of elderly persons. Experience over the years in Nigeria has left no doubt that there is no magic bullet for geriatric non-communicable diseases hence the need for all possible determinants of geriatric non-communicable diseases morbidity profile at all levels of healthcare as part of the search for an effective intervention strategy. The burden of non-communicable diseases among geriatric patients in the study area is largely unknown. Hence determination of noncommunicable diseases morbidity burden among this special group of elder citizens in a rural Nigerian secondary health institution is needed. The authors therefore sought to study the prevalence and pattern of non-communicable diseases among geriatric Nigerians in a rural hospital in resource-constrained setting of Eastern Nigeria.

\section{Materials and Methods}

This study was a descriptive hospital-based study carried out from June 2008 to June 2011 at St. Vincent De Paul Hospital, Amurie-Omanze, a rural General Hospital in Isu Local Government Area of Imo state, South-Eastern Nigeria. The Hospital renders twenty four hours service daily including public holidays to the community and its environs.

The clinical records of geriatric patients who presented each day to the hospital were collected and entered into a data collection schedule sheet. The geriatric patients who needed highly specialized diagnostic investigations and management were referred out and excluded from the study. Sample size estimation was determined using the formula[21] for estimating minimum sample size for descriptive studies when studying proportions with entire population size $<10,000$ using estimated population size of 600 geriatric patients based on the previous annual geriatric patients hospital attendance records.[11] The estimated minimum sample size assuming 50\% expected variance in estimating the proportion of the geriatric patients attending the hospital gave final minimum sample size estimate of 234 geriatric patients. However, selected sample size of 286 geriatric patients was used based on the time frame of the study.

Data extracted for analysis included bio-data such as age, sex and diagnoses. Diagnosis of NCDs was based on clinical methods of medical clerkship: subjective complaints, objective findings, laboratory and radiodiagnostic investigations. Relevant laboratory and radiodiagnostic investigative studies not available in the study Centre were done at Federal Medical Centre, Owerri, Imo State University Teaching Hospital, Orlu, and Hi-tech Laboratory, Owerri, Nigeria.

The authors' defined geriatric patients as those aged 65 years and above. Non-communicable diseases as those diseases that are not communicable and are associated with genetic predisposition, related to lifestyle with multifactorial environmental factors examples include hypertension, diabetes mellitus, musculoskeletal disorders, malignancy etc.

\section{Statistics}

The results obtained were analysed using Statistical Package for Social Sciences (SPSS) software version 13.0, Microsoft Coperation, Inc. Chicago, IL, USA for the calculation of mean, frequencies and percentages.

\section{Results}

Eight hundred and seventy two patients out of a total patients population of 9885 were 65 years and above. The geriatric population constituted $8.8 \%$ of total patients' 
population. Five hundred and thirty $(60.8 \%)$ of geriatric health problems were due to communicable diseases; two hundred and eighty-six $(32.8 \%)$ were due to noncommunicable diseases and fifty-six (6.4\%) resulted from accidents, trauma and injuries.[Table 1]

Of the 286 patients who had non-communicable diseases, the age ranged from 65 years to 98 years with mean age of $74 \pm 3.4$ years. There were $176(61.5 \%)$ males and $110(38.55)$ females with male to female ratio of $1.6: 1$ [Table 2].

The top five non-communicable disease were hypertension 192 (67.1\%), musculoskeletal disorders 126 (44.1\%), dyspepsia 99 (34.6\%), visual impairment 96 (33.6\%), and diabetes mellitus $25(8.7 \%)$ [Table 3]

Table 1. Distribution of health problems of geriatric patients

\begin{tabular}{ccc}
\hline Health problems & Number & Percentage \\
\hline Communicable diseases & 530 & 60.8 \\
Non-communicable diseases & 286 & 32.8 \\
Accident, trauma and injuries & 56 & 6.4 \\
Total & 872 & 100.0 \\
\hline
\end{tabular}

Table 2. Age and sex distribution of the geriatric patients with noncommunicable disease.

\begin{tabular}{ccc}
\hline Age (years) & Male & Female \\
\hline & Number $(\%)$ & Number $(\%)$ \\
$65-74$ & $66(37.5)$ & $39(35.5)$ \\
$75-84$ & $70(39.8)$ & $38(34.5)$ \\
$\geq 85$ & $40(22.7)$ & $33(30.0)$ \\
Total & $176(100.0)$ & $110(100.0)$ \\
\hline
\end{tabular}

Table 3. Frequency distribution of the geriatric NCDs.

\begin{tabular}{ccc}
\hline Diagnosis & Frequency & Percentage \\
\hline Hypertension & 192 & 67.1 \\
Musculoskeletal disorders & 126 & 44.1 \\
Dyspepsia & 99 & 34.6 \\
Visual impairment & 96 & 33.6 \\
Diabetes mellitus & 25 & 8.7 \\
Chronic inflammatory airway & 16 & 5.6 \\
diseases & 16 & 5.6 \\
Bladder outlet obstruction & 14 & 4.9 \\
Hernias & 11 & 3.8 \\
Stroke (cerebrovascular accident) & 3 & 1.0 \\
Breast tumours & 3 & 1.0 \\
Haemorrhoids & 2 & 0.7 \\
Parkinsonism & 2 & 0.7 \\
Appendicitis &
\end{tabular}

*Multiple diagnoses were recorded for some patients.

*Percentages represent proportion of the geriatric population with $\mathrm{NCDs}(\mathrm{N}=286)$.

\section{Discussion}

This study has shown that communicable diseases contributed $60.8 \%$ of the total geriatric health problems, non-communicable diseases accounted for $32.8 \%$ while $6.4 \%$ resulted from accidents, trauma and injuries. This pattern of distribution of geriatric health problems is similar but varied in proportions with reports among geriatric patients in Ibadan, Nigeria [13] and India. [22] However, this study suggests that communicable and non-communicable diseases are increasingly being diagnosed among geriatric patients in the study area. [11,12] This shows that the contribution of geriatric morbidity from non-communicable diseases is overshadowed by the prominence of communicable diseases but the trend is changing. Noncommunicable diseases accounted for $32.8 \%$ of the overall geriatric health problem in this study. This proportion is within the prevalence range of $26 \%$ - $34 \%$ described for the burden of NCDs in developing countries. ${ }^{[19]}$ The Global Burden of Disease Study suggested that by the year 2020, the proportion of burden of non-communicable diseases in sub-Saharan Africa will increase to somewhere between $26 \%$ and 34\%.[19] In natural aging process, apart from immutable risk factor of age many of the mutable risk factors for non-communicable diseases are lifestyle-related and can be prevented $[7,18]$ There is therefore an urgent need for early clinical and public health interventions for non-communicable diseases in the study area.

Hypertension was the most common cause of noncommunicable diseases morbidity among the study population. This finding has buttressed the reports from Ibadan, Nigeria where hypertension was the most prevalent non-communicable diseases among geriatric Nigerians.[5,16] and is similar to reports from other parts of the world such India. [22] In United States of America, hypertension was documented as the most common diagnosis among geriatric patients' physicians' office visits. [6] According to the reports $[12,13,23]$ from Nigeria, hypertension has become a clinical and public health problem in the country and a major cause of cardiovascular diseases morbidity and mortality.[7,23] Apart from agerelated cardiovascular changes, aging can lead to increased sedentary living, excessive food intake and reduced food metabolism. All these constitute risk factors for hypertension among the elderly population. Effort should therefore be made to tackle the burden of hypertension among this special group of elder citizens in rural areas who are living in resource-poor communities. The interventional preventive strategies will improve their quality, quantity and duration of life and invariably reduce the incidence and health costs associated with geriatric hypertension.

The second most common cause of geriatric morbidity from non-communicable diseases was musculoskeletal disorders. Musculoskeletal disorders have been reported as common health problem affecting about half of persons aged 65 years and above[13,22,26,27] and it leads to 
incorrect biomechanics, impaired mobility and increase the risk of developing skeletal and muscular deconditioning.[27,28] Although, musculoskeletal disorders are leading cause of disability in elderly persons, it is probably not one disease but several diseases having similar clinical and pathophysiological features. [28] However, age-related musculoskeletal changes predispose and promote the development of MSDs among the elderly persons. Just as the hair turns grey and eyesight begins to fade so the bones that form the joints and articulate with one another tend to become rough and painful. This is probably due to various degenerative changes in the musculoskeletal system leading to decreased functional reserves and ability to adapt to physiological, physical and psychosocial challenges. The musculoskeletal system is especially prone to degeneration in the elderly and is therefore susceptible to decompensation.[5,28]

The third most common cause of geriatric morbidity from non-communicable disease was dyspepsia. This was probably in part due to irrational use of non-steroidal antiinflammatory drugs for musculoskeletal disorders which was the second most common NCDs among the study population amidst other diverse causes. Although nonsteroidal anti-inflammatory drugs (NSAIDs) are commonly prescribed or procured in the study area as self-medicament for the management of musculoskeletal pain of inflammatory origin such as in musculoskeletal disorders, they are not without adverse effects, most notably upper gastrointestinal toxicity such as dyspepsia. [29, 30] The widespread and unsupervised use of NSAIDs whether prescribed by a physician or as a form of self-medication increases the risk of gastrointestinal adverse effects. Despite the age-related anatomic and physiological changes in the gastrointestinal system, pharmacologic, dietary and behavioural factors are contributory.[31] Accordingly, NSAIDs-induced gastropathy was reported as the most prominent cause of geriatric dyspepsia.[32] On the basis of the risk of gastrointestinal toxicity and associated morbidity, preventive strategies to minimize the adverse effects of NSADs-induced gastropathy among geriatric patients who have MSDs and on chronic NSAIDs should be done when such medications are prescribed. This therefore has implications for clinical decision making and rational drug use during clinical encounter with geriatric Nigerians with musculoskeletal disorders.

\section{Implications of the Study}

Morbidity profiles from non-communicable diseases have been changing in rural areas of Nigeria in recent decades due to urbanization and demographic changes. It does appear that physiological and structural age-related changes are inevitable. On the other hand, it seems that behavioural factors can have a profound influence on the extent and speed of these age-related changes. It is therefore important for clinicians to be aware of these subtleties because they can clearly influence both the quality and quantity of care delivered to geriatric patients. Physicians in Nigeria should therefore ask specific question of their geriatric patients in order to uncover noncommunicable disease problems in the early stages. This will enable geriatric patients in Nigeria benefit from remarkable increases in longevity reportedly observed among their counterparts in developed countries. This study therefore has substantial implications for geriatric patients' health education, promotion, maintenance, counselling, risk reduction and medical decision-making such as screening protocols for non-communicable diseases among others.

\section{Limitations of the Study}

The limitations of this study are recognized by the authors. First and foremost the limitations imposed by the descriptive nature of the study are recognized. The descriptive nature of the study therefore limited the evaluation of cause-effect associations or relationship between lifestyle factors and geriatric hypertension as well as the associations between dyspepsia and excessive consumption of NSAIDs. However, this study stimulates the need for analytical and longitudinal studies in this area. This would enable a quasi cause-effect relationship to be drawn and also for a reliable and valid conclusion to be ascertained.

This study was designed to describe the prevalence and pattern in relation to NCDs rather than association with specific NCDs or socio-demographic geography. Noncommunicable diseases are vast medical problems. In addition, the sample size for each NCDs entity in this study is relatively very small for specific socio-demographic analysis.

The sample was drawn from hospital attendees in the study area as only geriatric patients who presented to the clinic were studied. Thus extrapolation and generalization of the results of the study to the entire population should be done with utmost caution because the findings may not be a true representation of what may be obtained in the community.

\section{Conclusion}

This study has shown that geriatric patients in the study area suffer non-communicable diseases with most common being hypertension, musculoskeletal disorders and dyspepsia. There is therefore the need for preventive action against the scourge of geriatric non-communicable diseases.

\section{Future Research Direction}

Further researches are suggested to determine associations between lifestyle factors and geriatric hypertension as well as between geriatric dyspepsia and excessive consumption of NSAIDs in the study area. This will provide clinical and epidemiological data for consultative purposes. 


\section{Acknowledgements}

The authors are grateful to Rev. Sister Francisca Eya of St. Vincent de Paul Hospital, Amurie-Omanze for permission for the study.

\section{References}

[1] Shapiro DP. Geriatric demographics and the practice of Otolaryngology. Ear, Nose, Throat J 1999; 78: 418-421.

[2] Guralnik J, Havlik R. Demographics. In: Beers MH, Berkow $\mathrm{R}$ editors. The Merck Manual of Geriatrics, 3rd edition. New Jersey(USA) Merck \& Co Inc White house station 2001: p.26.

[3] Abanobi OC. Health: Wellness and illness states. Biological, Social, Cultural, Environmental, Nutritional, Behavioural and Health System Factors. Owerri, Opinion Research Communications Inc 2005; 57-65.

[4] Mobbs C. Biology of aging. In: Beers MH, Berkow R editorss. The Merck Manual of Geriatrics, 3rd edn. New Jersey(USA) Merck \& Co Inc White house station 2001:p. 25.

[5] BreeJohnston C, Lyons WL, Covinsky KE. Geriatric Medicine. In: McPhee SJ, Papadakis MA, Tierney LM editors. Current Medical Diagnosis and Treatment, 42nd edn., New York. Lange Medical Books 2003; p.41-46.

[6] Chobanian AV, Bakris GL, Black HR, Cushman WC, Green LA, Izzo JL et al. The seventh report of the Joint National Committee on Prevention, Detection, Evaluation and Treatment of high blood pressure: The JNC VII report. JAMA 2003; 289(19):2560-2572.

[7] Akinkugbe OO. Non-communicable diseases in Nigeria, The next epidemics: Nigeria preparedness. Third Biennial Abayomi Bamidele Memorial Lectures. Niger J Clin Pact $2000 ; 3: 37-42$

[8] Murray CJL, Lopez D. Global mortality, disability and the contribution of risk factors: Global Burden of Disease Study. Lancet 1997; 349: 1436-1442.

[9] Yach D, Hawkes C, Gould CL, Hofman KJ. The global burden of chronic diseases: Overcoming the impediments to prevention and control. JAMA 2004; 291: 2616-2622.

[10] Alberti G. Noncommunicable diseases: tommorows pandemics(Editorial). Bull World Health Organ 2001; 79:907

[11] Iloh GUP, Obikwu CE, Amadi AN. Common Geriatric Morbidity from Communicable Diseases in a Rural Hospital in Eastern Nigeria. Niger J Med 2012; 21: 231-236.

[12] Iloh G, Amadi AN, Awa-Madu J. Common geriatric emergencies in a rural hospital in South-Eastern Nigeria. Niger J Clin Pract 2012; 15:333-7.

[13] Adebusoye LA, Ladipo MM, Owoaje ET, Ogunbode AM. Morbidity pattern amongst elderly patients presenting at a primary care clinic in Nigeria. Afr J Prm Health Care Fam Med 2011; 3(1).

[14] Omran AR. The epidemiologic transition: A theory of the epidemiology of population change. Bull World Health
Organ 2001; 79: 161-170.

[15] Okeahialam BN, Ogbonna C, Otokwula AE, Joseph DE, Chuwak EK, Isiguzoro IO. Cardiovascular Epidemiological Transition in a Rural Habitat of Nigeria: The Case of Mangu Local Government Area. West Afr J Med 2012; 31: 14-18.

[16] Nnebue CC. The epidemiologic transition: Policy and planning implications for developing countries. Niger J Med 2010; 19(3): 250-256.

[17] Foliaki S, Pearce N. Changing pattern of ill health for indigenous people. BMJ 2003; 327: 406-407.

[18] Tucker KL, Buranapin S. Nutrtion and Aging in Developing Countries. Journal of Nutrition 2001; 131: 2417S-2423S.

[19] Unwin N, Setel P, Rashid S, Mugusi F, Mbanya JC, Kitange $\mathrm{H}$, et al. Non-communicable diseases in sub-Saharan Africa: where do they feature in the health research agenda? Bull World Health Organ 2001; 79(10): 947-953.

[20] Iyaniwura CA. Health promotion in general practice in Ogun state. Niger Med Pract 2004; 45: 29-42.

[21] Araoye MO. Sample size determination. Research Methodology with Statistics for Health and Social Sciences, Ilorin, Nathadex Publishers, 2004; p.115-121.

[22] Agrawal S, Deo J, Verma AK, Kotwal A. Geriatric health: Need to make it an essential element of primary health care. India J Public Health 2011; 55: 25 - 9.

[23] Iloh GU, Ofoedu JN, Njoku PU, Amadi AN. Blood pressure control among geriatric Nigerians with essential hypertension in a rural hospital in South-Eastern Nigeria. Port Harcourt Med J 2013; 7: 50-58.

[24] DelGuidice A, Pompa G, Ancella F. Hypertension in the elderly. J Nphrol 2010; 1S: S61-S71.

[25] Sawabe M. Vascular aging: from the molecular mechanism to clinical significance. Geriatr Gerontol Int 2010; 1: S213 S220

[26] Mukhopadhyay K, Singh R. Common Geriatric Cases Seen by a General Practitioner in an Urban Area of Jharkhand State, India. J Fam Med Primary Care 2012;1: 164 - 5.

[27] Tsou IY, Ching HH. The bone and joint decade 2000-2010 for prevention and treatment of musculoskeletal disease. Ann Acad Med Singapore 2002; 31: 69-70.

[28] Ettinger W. Aging and osteoarthritis In: Beers MH, Berkow $\mathrm{R}$ editors. The Merck Manual of Geriatrics, 3rd edn. New Jersey(USA) Merck \& Co Inc White house station 2001: p. $467-472$.

[29] Mamdani M, Rochon P, Juurlink D. Observational study of upper gastrointestinal haemorrhage in elderly patients given selective cyclo-oxygenase 2 inhibitors or conventional nonsteroidal anti-inflammatory drugs. BMJ 2002; 325: 619-624.

[30] Page J, Henry D. Consumption of NSAIDs and the development of congestive heart failure in elderly patients: An under recognized public health problem. Arch Intern Med 2000; 160: 777-784.

[31] Iloh GUP, Chuku A, Dike OJ, Amafili OP, Nnaji BC. Burden of Limitations of Activities of Daily Living Among Geriatric Nigerians with Musculoskeletal Disorders in a Resource-Limited Nigerian Primary Care Clinic in Eastern 
Nigeria. American Journal of Health Research 2013; 1: 916.
[32] Laine L. Approach to non-steroidal anti-inflammatory drug use in the high risk patients. Gastroenterology 2001; 120: 594-606. 